\title{
Localized surface-ice weakness on a glacial ice runway
}

\author{
R. M. LANG \\ Department of Physics, Pacific Lutheran University, Tacoma, Washington 98447-0003, U.S.A.
}

George L. Blaisdell

U.S. Army Cold Regions Research and Engineering Laboratory, 72 Lyme Road, Hanover, New Hampshire 03755-1290, U.S.A.

\begin{abstract}
Following construction of a glacial ice runway on the Ross Ice Shelf, Antarctica, and prior to flight operations, the runway was proof-rolled. The proof exercise was designed to simulate typical heavy aircraft. Initial testing produced numerous brittle surface failures in the runway ice. Thin sections of ice cores taken from the failed areas showed large crystals ( $c$ axis vertical) of clear, blue ice with long, vertical bubbles, indicative of ice formed directly from meltwater. Uniaxial unconfined compression tests on core samples were used to compare runway ice strength with published data for polycrystalline laboratory ice. Since the frequent failure of surface ice had not been expected, it was critical to understand the formation and mechanical properties of the weak ice to prevent its occurrence in the future and to strengthen the existing problem areas. We discuss the likely scenarios for development of weak ice on the airstrip and the physical properties of this type of ice. Also, the procedure used to repair successfully the runway surface is described, which culminated in test flights, followed by full flight operations.
\end{abstract}

\section{INTRODUGTION}

During the November 1992 post-construction phase of the Pegasus glacial ice runway for McMurdo Station, Antarctica, the runway was proof-rolled for the load of a C-141 aircraft after final grading. For final grading of the ice surface, a Caterpillar 14G grader equipped with a chisel-tooth blade was used. The blade was designed with an alternating tall- and short-tooth pattern to assist in cleaning the surface of all debris. The included angle of the cutting teeth was $42^{\circ}$ and side-relief angles were $41^{\circ}$. A laser-guidance system assisted in producing an accurate grade even when the grader operator had great difficulty seeing well enough to drive in a straight line. Snow and ice debris were removed from the runway surface with a Rolba rotary snow-blower. (For a more complete

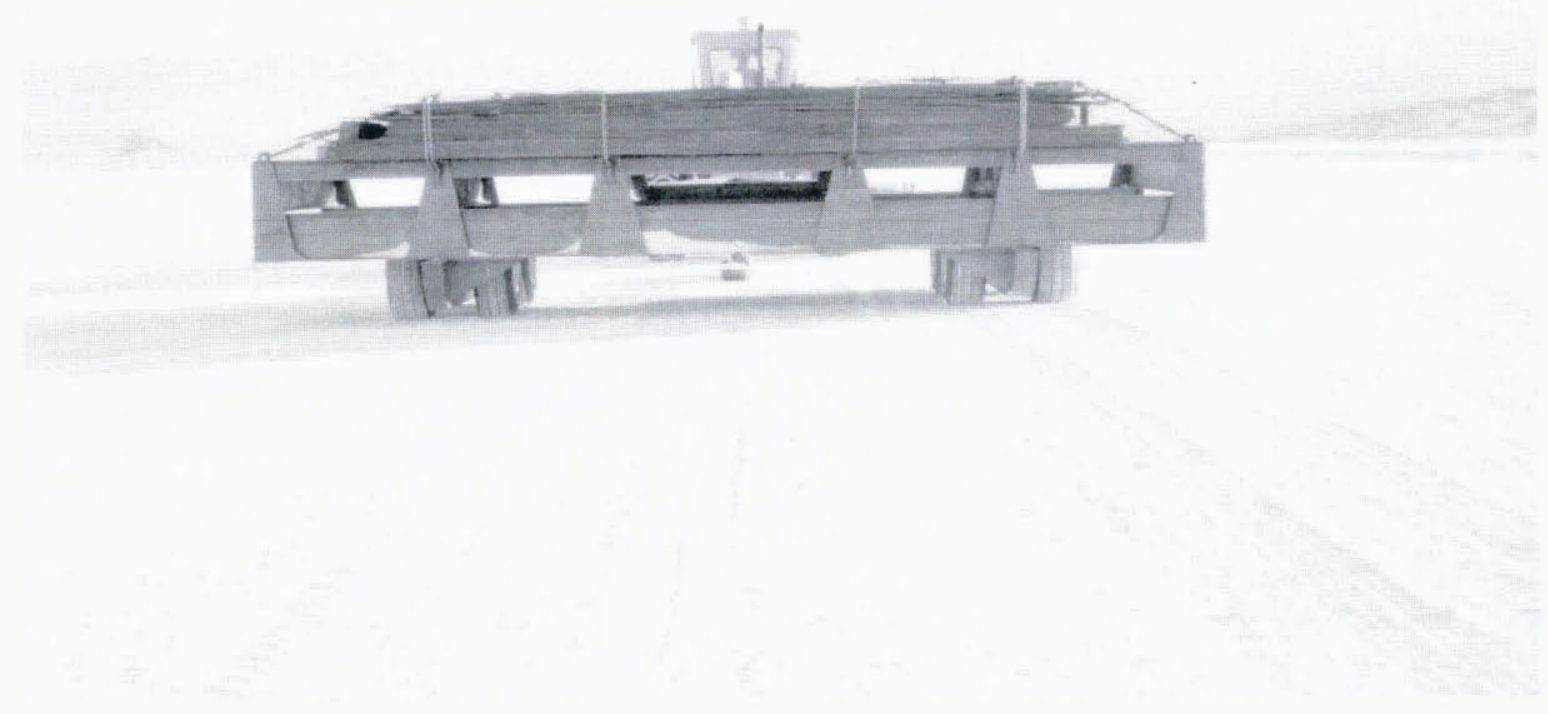

Fig. 1. Proof cart configured to simulate the main landing gear of a C-141 aircraft. 


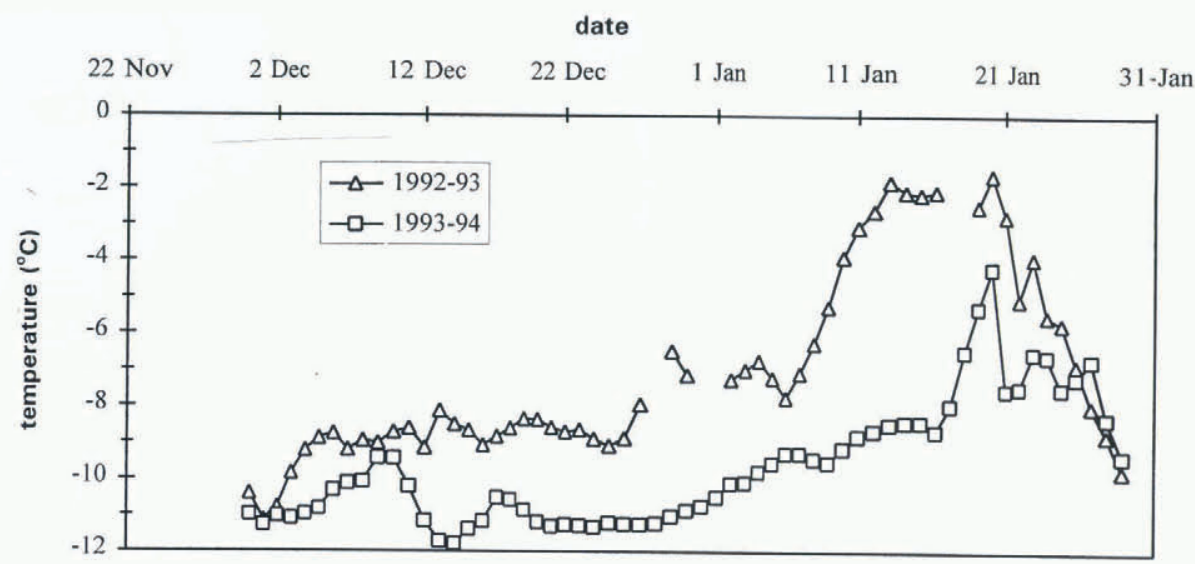

Fig. 2. Surface-ice lemperature profile through time at the $1610 \mathrm{~m}$ marker on the Pegasus runway, austral summers 1992-93 and 1993-94.

description of the runway-surface preparation see Blaisdell and Lang (1994).)

A proof cart was configured with eight C-141 wheels placed in the exact arrangement as in the main landing gear of a C-141 aircraft (Fig. 1). The cart was loaded with structural steel to the maximum C-141 main-gear load plus $18 \%$. The maximum take-off weight of the C-141 is $1063 \mathrm{kN}$ ( $5 \%$ of that load carried by the nose wheels) and the main gear tires operate at $1.38 \mathrm{MPa}$. During testing, the proof cart had a gross weight of $1192 \mathrm{kN}$ with the tires inflated to $1.8 \mathrm{MPa}$.

The C-141 proof-rolling in November 1992 produced many near-surface failures in the runway ice. These failures were brittle; the ice shattered under the tires as the proof cart passed. Ice cores showed that the surface ice was not composed of the typical milky white glacial shelf ice that forms naturally from snow under compression, but instead it was clear blue ice with long, slender, vertical bubbles, indicative of ice formed directly from freezing water. During the 1990-91 austral summer, construction activities on the runway had caused localized surface melting as the protection of the snow cover was removed. Also, meltwater had been used to fill a large, natural depression between approximately $1200 \mathrm{~m}$ and $1800 \mathrm{~m}$ along the runway, in order to avoid lowering the entire runway surface to the minimum grade. Depths of this meltwater-derived ice ranged from a few centimeters to more than $1 \mathrm{~m}$. Thin sections of this ice revealed large, vertically oriented crystals ( $c$ axis perpendicular to the ice surface), typical of lake ice. Every area of surface failure on the runway occurred in this "blue" ice. The ice temperature was less than $-11^{\circ} \mathrm{C}$ at depths near the surface during November (Fig. 2).

After the C-141 proof-rolling, all areas of the failed ice were patched with a slush comprising the broken-up ice from the pothole, snow and cold fresh water. The ice patches were satisfactorily retested with the proof cart after a $48 \mathrm{~h}$ freezing period.

Three months later, in February 1993, the runway was proof-rolled for a C-130 load plus $28 \%$. The cart was reconfigured to represent the C-130 main landing gear and loaded to $883 \mathrm{kN}$ with approximately $221 \mathrm{kN}$ on each tire. The maximum take-off weight of the C-130 is $689 \mathrm{kN}$. C-130 tires were unavailable so the C-141 tires were used at a pressure of $1.1 \mathrm{MPa}$, compared to the actual C-130 tire pressure of $0.7 \mathrm{MPa}$. The proof cart had an individual tire contact patch of $2168 \mathrm{~cm}^{2}$ compared to the $\mathrm{C}-130$ area of $2890 \mathrm{~cm}^{2}$. During this test, the number of surface ice failures reduced significantly. In the areas that failed, the surface ice appeared to be less brittle than in November, possibly indicating that some type of annealing occurred when the ice was warm during the peak of the austral summer (Fig. 2). All failed surface areas were patched with the ice-snow-water composite and successfully retested with the C-130 proof cart. On 6 February, the Pegasus runway tested successfully with a fully loaded LC-130 landing on wheels (skis retracted). On 8 February 1993, the airstrip became fully operational for C-130 (wheeled) flights.

The following austral summer, at the end of January 1994, the Pegasus runway was proof-rolled for C-141 loads with no ice failures. Ice temperatures during this period were less than $-10^{\circ} \mathrm{C}$ (Fig. 2). On 7 February 1994, a fully successful C-141 flight test was performed.

This paper addresses possible scenarios for the development of the weak ice on the airstrip and the physical properties of this type of ice. Ice-core samples were extracted from the problem areas and thin sections were made. Uniaxial unconfined compression tests were run on the least-damaged core samples in order to determine how the ice compared to compressive strengths of laboratory ice. Since frequent surface-ice failure had not been expected, it was critical to understand the formation and mechanical properties of this weak ice in order to prevent its formation in the future, assure that our patching technique solved the problem, and to ascertain the probability that additional weak areas were present on the runway but had not been directly loaded by the proof cart.

\section{CHARACTERISTICS OF THE FAILED AREAS}

Only a slight perturbation of the proof cart was noticed when an ice failure occurred. We closely followed the cart during proof-rolling and noted that, when failure occurred, the ice seemed to suddenly turn to rubble in an area much larger than the contact area of a single tire (Fig. 3). In most cases, ice failure happened as a single rapid event and the proof cart quickly moved out of the crumbled area 


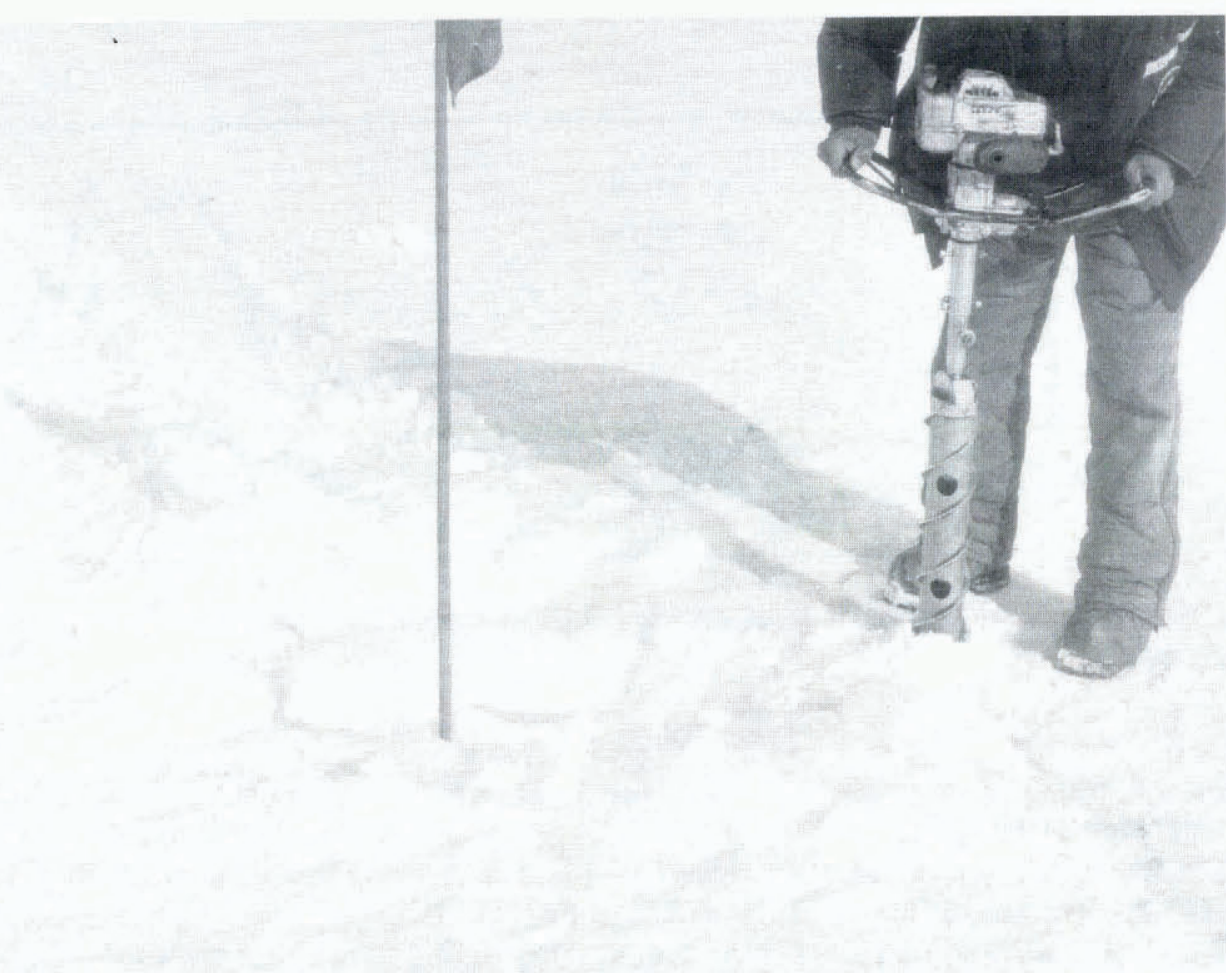

Fig. 3. Site of an ice failure caused during proof-rolling.

(where it only experienced minor sinkage) on to adjacent ice where it was supported on the surface. Occasionally, the proof cart would generate progressive ice failures as it moved forward until it found sound ice again.
We excavated the ice from failed areas and found that, macroscopically, most of the ice was very clear, contained many thin, elongated bubbles, and groups of these bubbles had a very distinct orientation (Fig. 4). Most
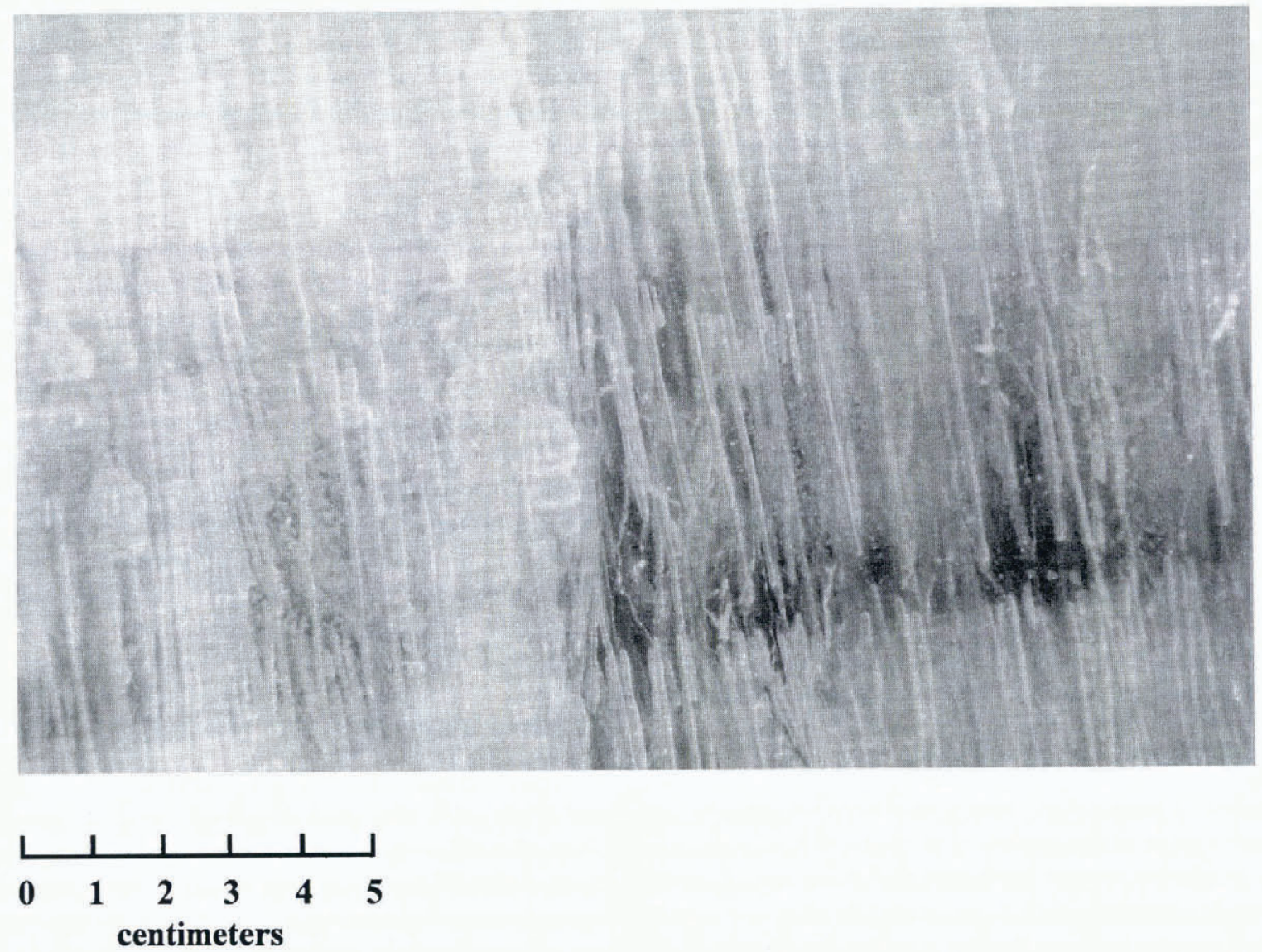

Fig. 4. Core sample of weak Pegasus runway surface ice. 
were vertical or nearly vertical. The ice exhibited concoidal, brittle fracture. Internal failure surfaces were revealed by reflected color bands. The depth of damaged ice ranged from a few centimeters to $1 \mathrm{~m}$. Excavation of the failed areas revealed that the ice had been broken into $0.1-0.3 \mathrm{~m}$ diameter chunks. Chunk size seemed to be quite uniform throughout the failed area and failure planes were random. At the base of the failed area there was a distinct boundary, usually with an undulating surface. In some instances, the surface was steeply sloped. The surface had a mottled appearance and hoarfrost often coated the ice above this boundary. The ice below the boundary was always completely undamaged and was clearly glacial in origin (formed by accumulation and subsequent consolidation of snow). Occasionally, the boundary could be traced back under the sidewalls of the excavated cavity and it was clear that a thin gap was present between the lower glacial ice and the overlying clear ice. Hoarfrost was present in this gap.

Ice in the sidewalls of a cavity was often greatly damaged but was much more finely cracked than the ice chunks in the excavated area and it remained in place. A preferred failure plane was associated with the cracked sidewall ice. These planes were usually sloped away from the main cavity. Numerous cracks radiated perpendicularly to the preferred failure planes and divided the ice into geometric blocks with large dimensions no greater than $0.1 \mathrm{~m}$.

Ice-core samples were taken at the following locations along the runway: north end $0 \mathrm{~m}$, corresponding to the direction of incoming flights), 1525, 1830 and $3050 \mathrm{~m}$ (south end). The cores were sketched indicating locations of pre-existing cracks, then wrapped in bubble wrap and stored for shipping at $-15^{\circ} \mathrm{C}$. The cores were shipped at $-15^{\circ} \mathrm{C}$, examined after shipping and then stored in a cold room at $-15^{\circ} \mathrm{C}$ until testing.

Most of the ice failures occurred between 1220 and $1830 \mathrm{~m}$ but failures also occurred, with lower frequency, near the 0 and $3050 \mathrm{~m}$ markers. A sketch of the runway and failed areas is shown in Figure 5.

\section{Thin-section analysis}

Thin sections of the ice cores were taken from the $0 \mathrm{~m}$ core, the $1830 \mathrm{~m}$ core and the $3050 \mathrm{~m}$ core. The $1830 \mathrm{~m}$ and $1525 \mathrm{~m}$ cores were macroscopically similar in structure. A complete profile of the $1830 \mathrm{~m}$ core is shown in Figure 6. The horizontal sections show the grain diameter and degree of extinction, and the vertical sections show the columnar nature of the ice when it is present. It is clear that the top half of the core was formed from meltwater; the upper $40 \mathrm{~cm}$ is characterized by a few 2-3 $\mathrm{mm}$ diameter, randomly oriented ice grains included in $8-35 \mathrm{~mm}$, equiaxed ice grains with the $c$ axes normal or nearly normal to the natural ice surface. At $5 \mathrm{~cm}$ depth, a horizontal discontinuity with crystals less than $0.5 \mathrm{~mm}$ in diameter is apparent (Fig. 6a). As the vertical grain boundaries are discontinuous at this gap, it is probable that either the top $3 \mathrm{~cm}$ or the ice below $3 \mathrm{~cm}$ experienced melting and recrystallization a second time.

The number of inclusions decreases with depth as shown in Figure $6 \mathrm{~b}$ and c. Between 18 and $35 \mathrm{~cm}$ depth, internal damage is apparent from the $2-7 \mathrm{~mm}$ radial cracks

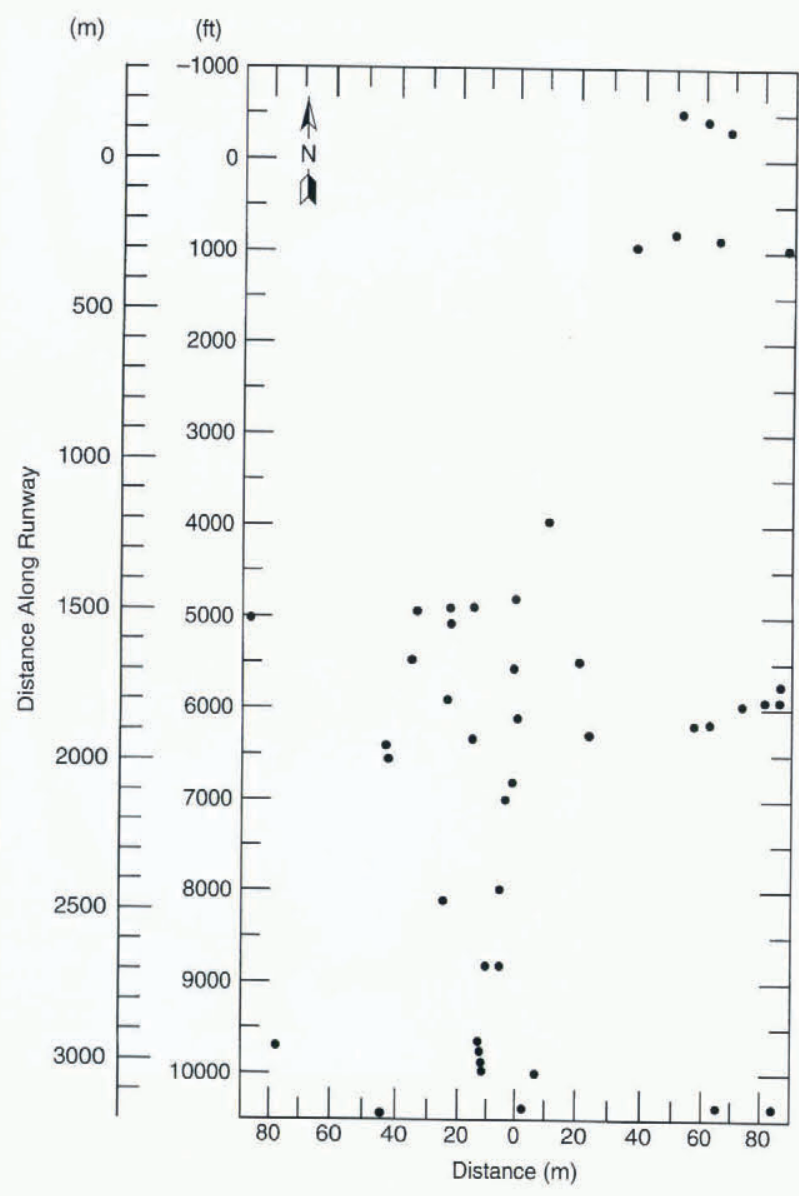

Fig. 5. Sketch of the Pegasus runway showing the location of surface-ice failure areas.

seen in the horizontal section (Fig. 6c). Grain boundaries are not well defined and the grains are more elliptical, with jagged boundaries in the horizontal plane. Bubbles increase in size with depth. At $40 \mathrm{~cm}$ depth, a distinct boundary occurs, delineating the meltwater ice to glacial ice transition (Fig. 6d). From 40 to $68.5 \mathrm{~cm}$ (bottom of the core; Fig. $6 \mathrm{~d}$, e and $\mathrm{f}$ ) the ice is characterized by $0.5-5 \mathrm{~mm}$ diameter, randomly oriented grains with some intrusion of melt at the boundary to a depth of approximately $45 \mathrm{~cm}$. The ice grains in the snow-derived ice below the boundary increase in size with depth (Fig. 6e and f).

At the south end of the runway, the ice in the upper horizon $(0-11.5 \mathrm{~cm})$ is randomly oriented and grain-sizes range from less than 0.5 to $9 \mathrm{~mm}$ (Fig. 7a). This uppermost layer appears to be firn. Beginning at about $32-34 \mathrm{~cm}$ depth, the ice grain-size begins to increase and this increase is relatively linear to a depth of $81-86.5 \mathrm{~cm}$. At the base of the core, the ice grains become more uniform and the average grain-size ranges from 5 to $10 \mathrm{~mm}$ (Fig. 7b). The origin of this ice also appears to be glacial but distinctly older, since crystals have coalesced to form larger grains. This core indicates that the south end of the runway perhaps had only small, localized areas of melt, as the thin sections do not reveal meltwaterderived ice. It is known from our own ice-temperature profiles at the north and south ends of the runway and the ambient temperature data from Automated Weather Stations located at both the north and south ends of the runway that typically the south end is $2^{\circ} \mathrm{C}$ cooler than the north end. Thin sections were not made between 10.5 and 


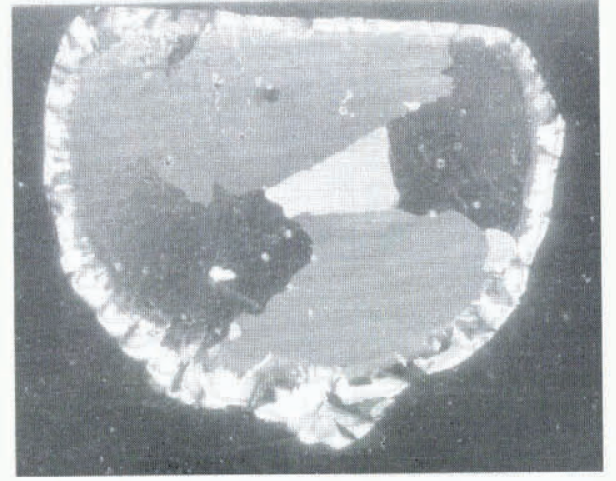

a

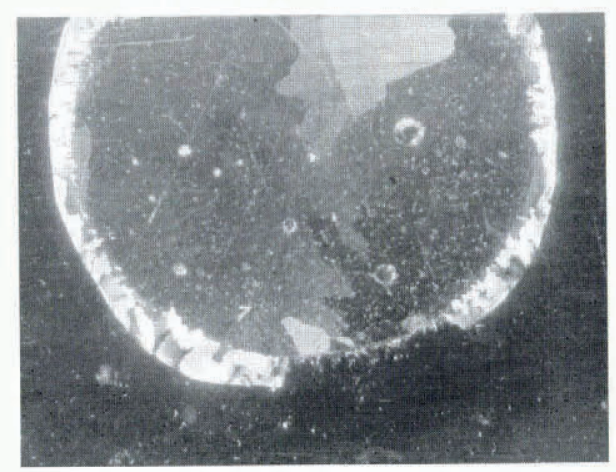

b

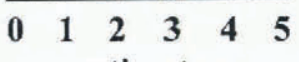
centimeters

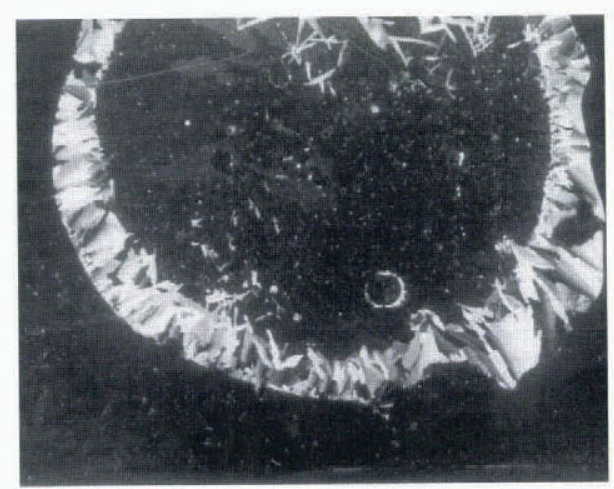

c
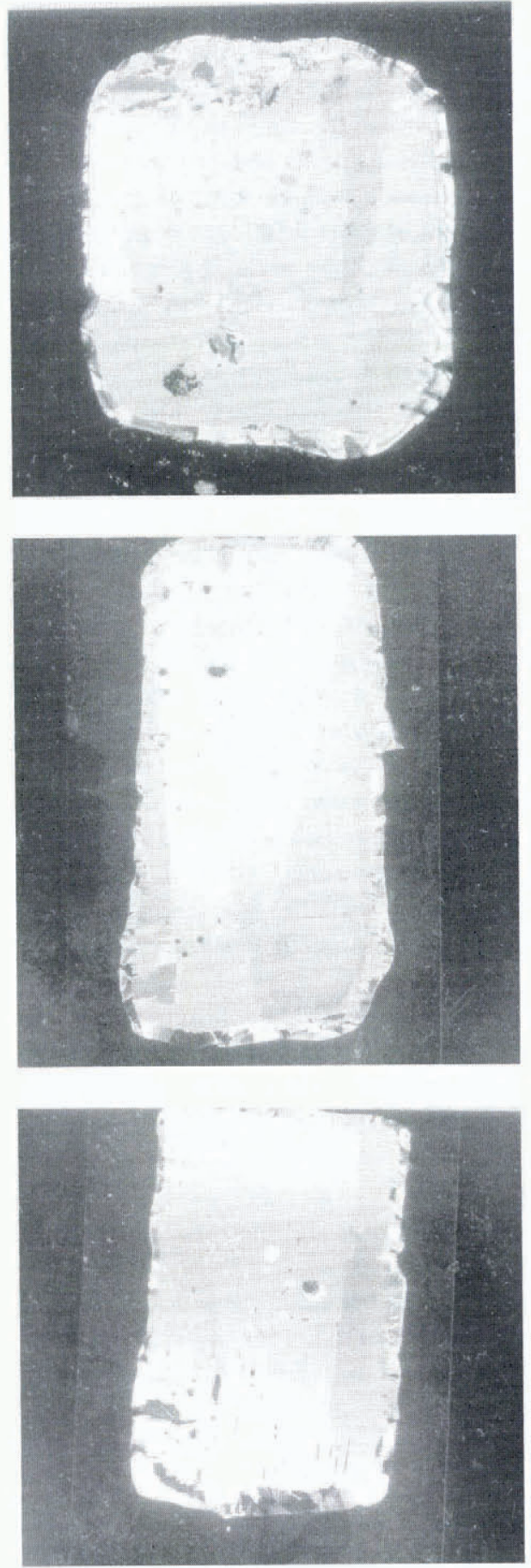

Fig. 6a-c. Horizontal (left) and vertical thin sections of core sample removed from the Pegasus runway surface at the $1830 \mathrm{~m}$ zone: a. $0-5 \mathrm{~cm} ; b .5-18 \mathrm{~cm} ; \mathrm{c.} .18-35.5 \mathrm{~cm}$.

$81 \mathrm{~cm}$; these specimens were preserved for compressivestrength testing.

At the north end $(0 \mathrm{~m})$ the core between 10.3 and $20.5 \mathrm{~cm}$ depth shows grain-sizes from less than 0.5 up to $5 \mathrm{~mm}$ in diameter and they appear to be somewhat oriented (Fig. 8). This ice also appears to be firn. Above this depth, the ice seemed to be meltwater-derived but the ice was too damaged to make a thin section.

\section{Unconfined compressive strength of core samples}

The results of unconfined compression tests on the icecore samples are shown in Figures 9 and 10. Most of the core samples were not suitable for testing since the ice shattered during the coring process. Few specimens with adequate length for compressive tests were available. The tested samples were extracted at the south end of the runway. Unfortunately, this is not the location of the weakest meltwater ice.

Figure 9 shows the stress-strain curve from ice at a depth of $10.5-15.5 \mathrm{~cm}$; this is snow-derived ice (i.e. glacial ice). The applied loading rate was $44.5 \mathrm{kN} \mathrm{s}^{-1}$, which is the approximate loading rate of the $\mathrm{C}$ - 141 tire rolling at $1.7 \mathrm{~km} \mathrm{~h}^{-1}$. During proof-rolling, the load cart moved about $3.3 \mathrm{~km} \mathrm{~h}^{-1}$. The test temperature was $-10^{\circ} \mathrm{C}$. Figure 9 shows a clear linear relationship between stress and 


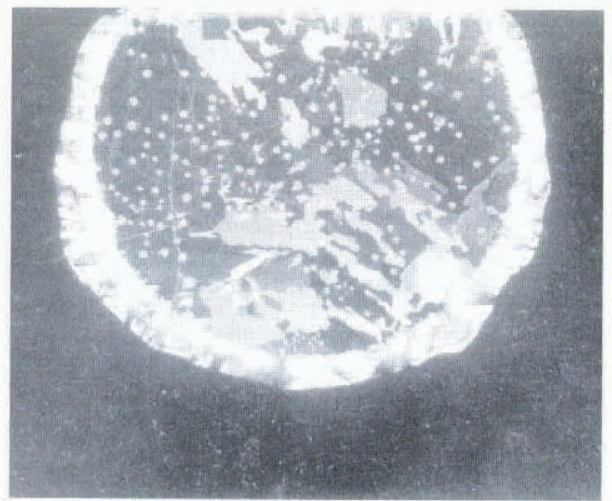

d

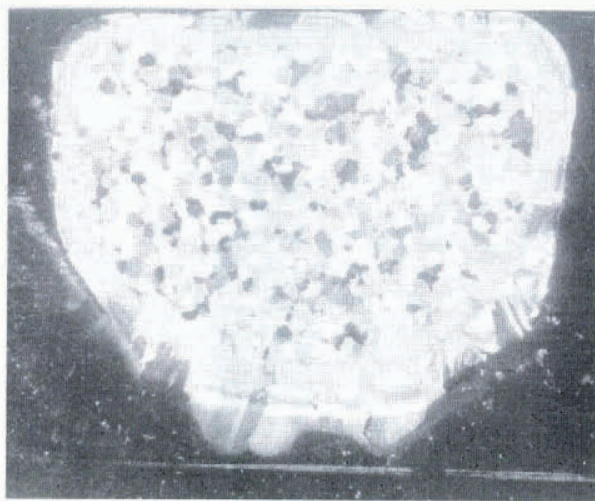

e
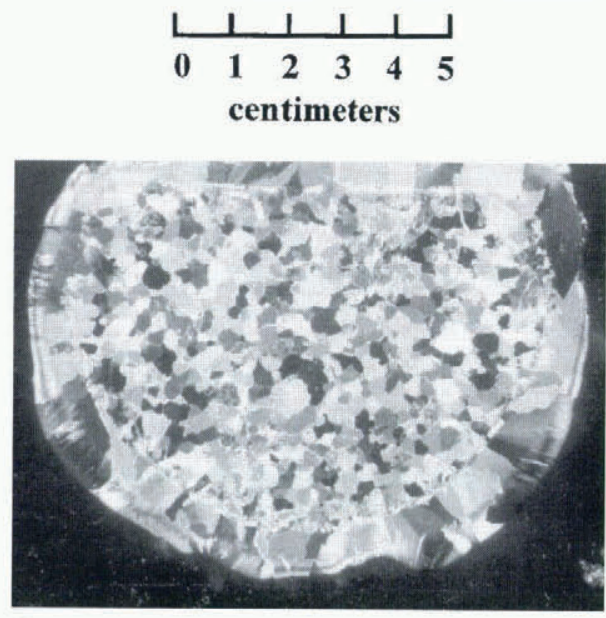

f
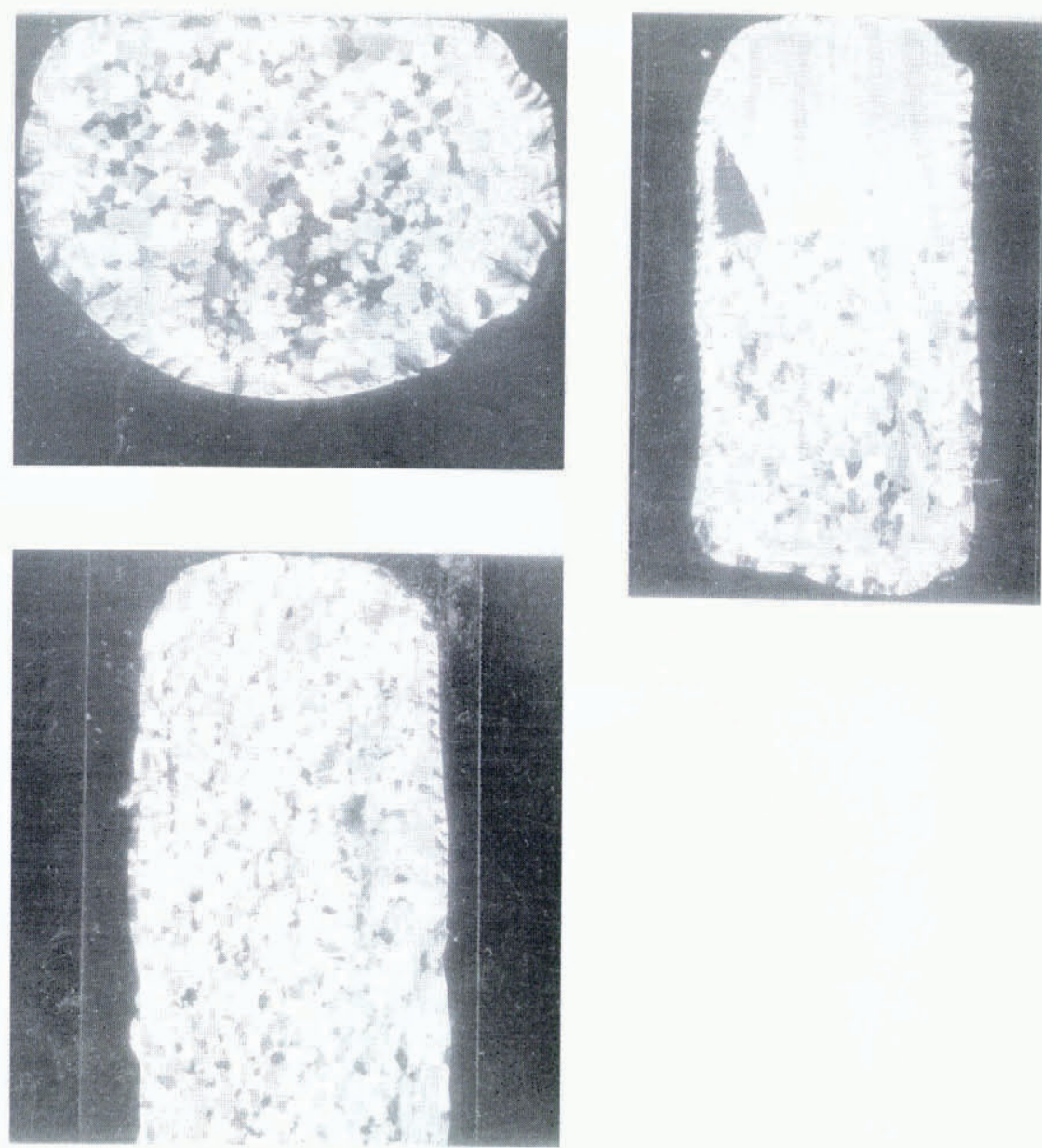

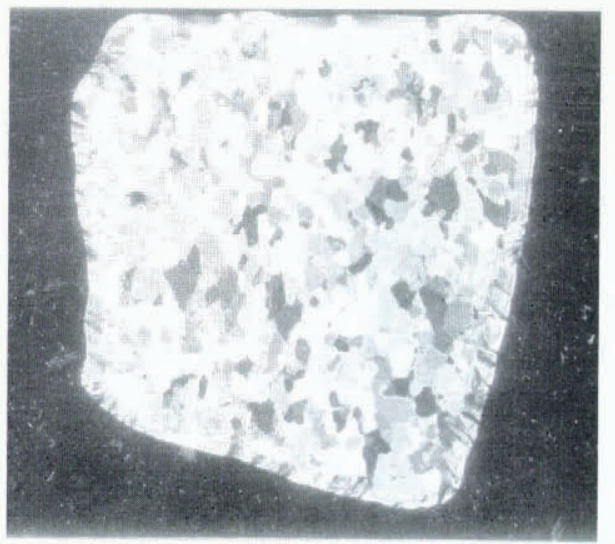

Fig. 6d-f. Horizontal and vertical thin sections of core sample removed from the Pegasus runway surface at the $1830 \mathrm{~m}$ zone: d. $35.549 .5 \mathrm{~cm} ;$ e. $49.5-63.5 \mathrm{~cm} ; f .63 .5-68.5 \mathrm{~cm}$.

strain to failure. This is indicative of a brittle failure mode in the ice. The failure stress is approximately $10 \mathrm{MPa}$.

The test results in Figure 10 are for an ice sample at a lower horizon $(20-27 \mathrm{~cm}$ deep). Its failure strength is approximately one-third that of the sample that was closer to the surface. This may be a grain-size effect; grain-size increased with depth at the south end of the runway. Larger grain-sizes generally correspond with reduced strength (see, e.g., Schulson, 1990). Figure 10 also depicts a strong linear stress-strain relationship, verifying that brittle failure should be expected in this load and temperature regime.

It is known that the mechanical properties of fresh- water ice depend on grain-size, grain orientation, grain type, temperature, strain rate and loading rate. Typically, it is reported in the literature that a decrease in ice temperature causes an increase in ice strength. For example, Nuttall and Morgenstern (1972) performed unconfined compression and biaxial (plane strain) tests on fresh-water ice, with the load applied parallel to the plane of the ice sheet. The tests at temperatures near melting and low strain rates did not induce fracture but exhibited creep failure (i.e. samples remained intact at maximum load). The tests at high strain rates produced ice fractures at maximum load. Maximum load at $-10^{\circ} \mathrm{C}$ was reported to be $7.6 \mathrm{MPa}$ but only $2.8 \mathrm{MPa}$ at $-1.5^{\circ} \mathrm{C}$ 


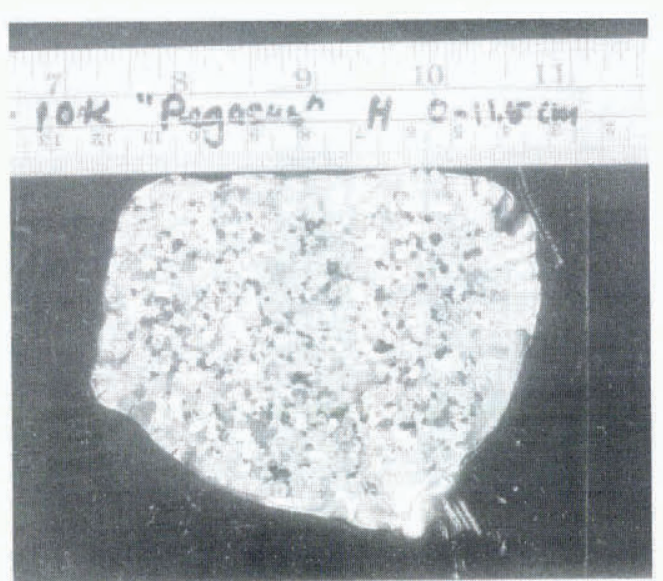

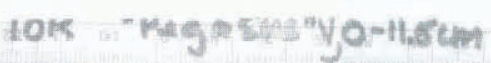

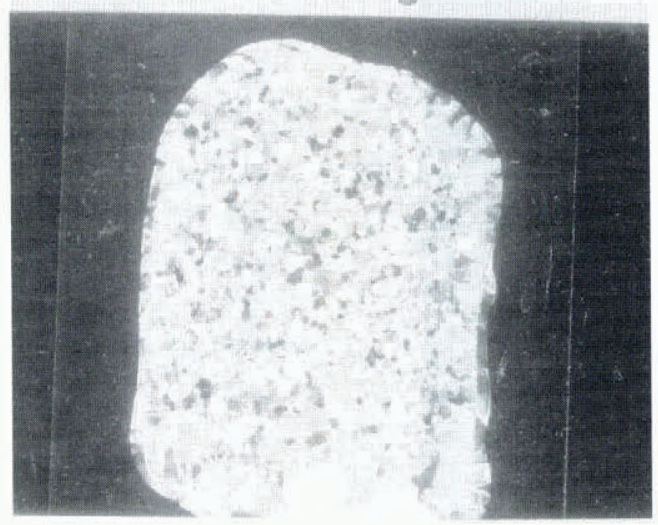

\begin{tabular}{llllll}
1 & 1 & 1 & 1 & 1 \\
\hline & 1 & 2 & 3 & 4 & 5
\end{tabular} centimeters
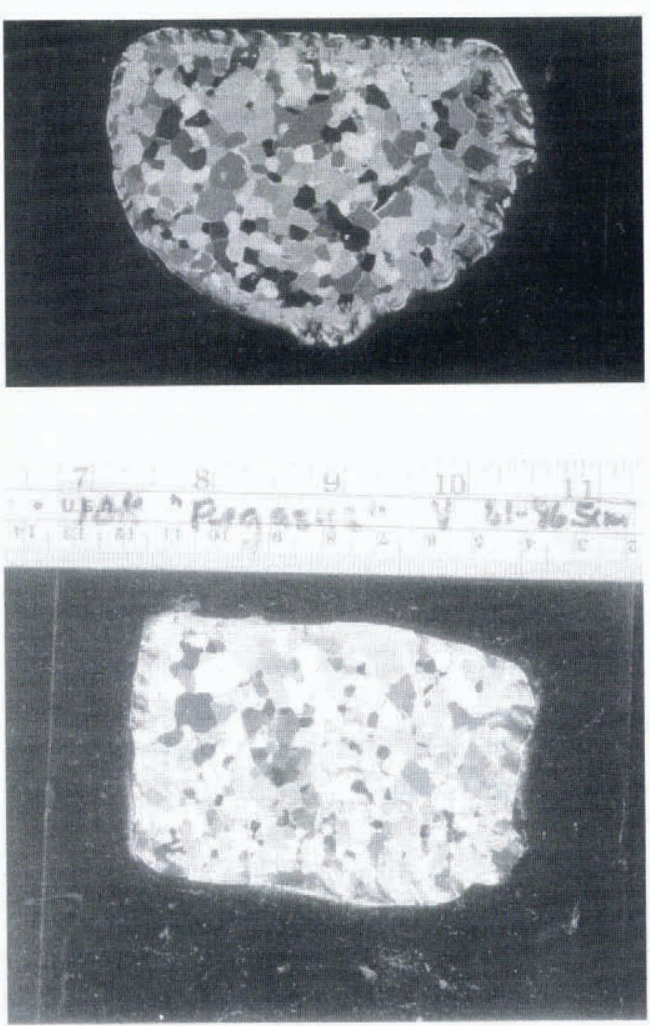

Fig. 7. Horizontal (top) and vertical thin sections of core sample removed from the Pegasus runway surface at the $3050 \mathrm{~m}$ zone (south end): $a .0-11.5 \mathrm{~cm} ; b .81-86.5 \mathrm{~cm}$.
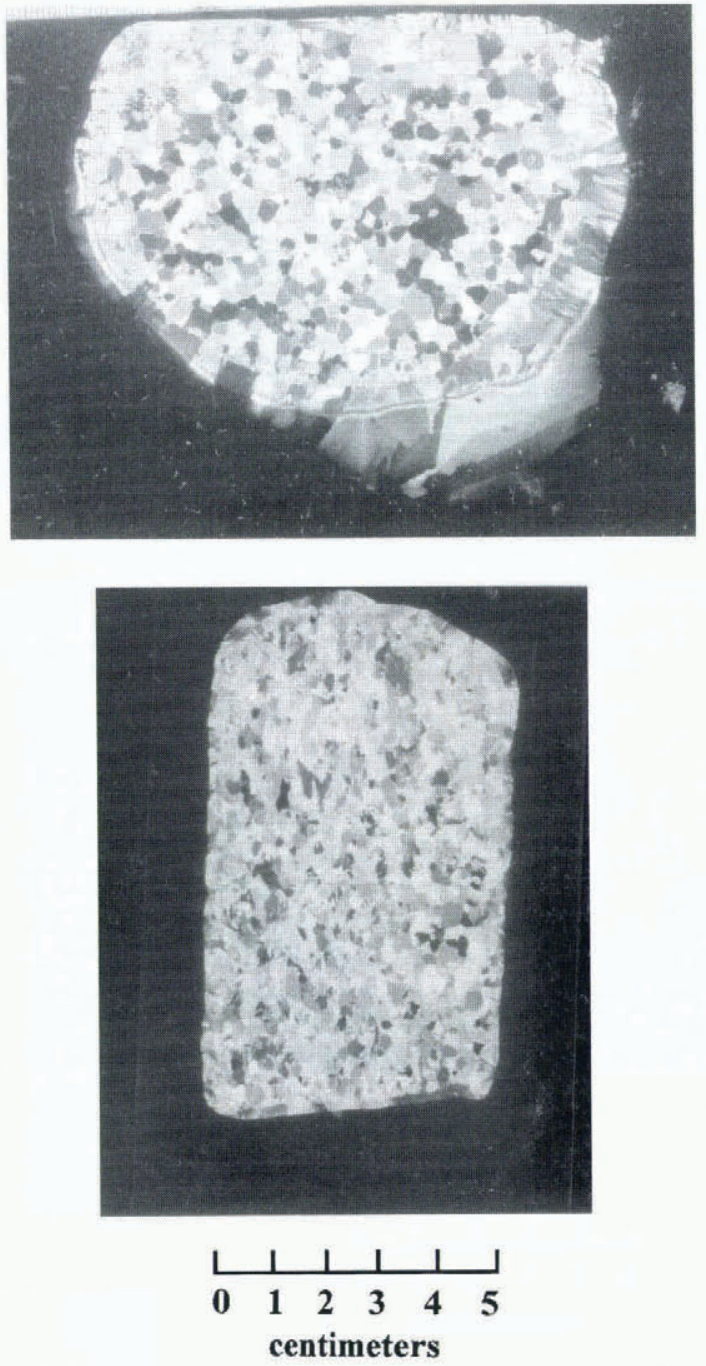

Fig. 8. Horizontal (top) and vertical thin sections at $10.3-20.5 \mathrm{~cm}$ horizon of core sample removed from the Pegasus runway surface at the $0 \mathrm{~m}$ zone (north end).

for unconfined tests. The ice in these tests was formed by freezing from the surface down and exhibited small grains at the surface and large grains at the base. In addition, the ice showed a preferential growth direction. The loading direction in these tests, with respect to the ice sheet, is $90^{\circ}$ opposed to the applied loading for our case with the proof cart. Loading transverse to the grain boundaries results in lower strength since equiaxed grains are weaker in transverse loading than in longitudinal loading (Nuttall and Morgenstern, 1972).

Schulson (1990) showed that the compressive fracture strength of granular, fresh-water ice increases with decreasing temperature and increasing strain rate within the ductile behavior range of ice. His stress strain curves exhibit the typical "knee" in the curve after the ultimate strength is reached and the macroscopic behavior is not heavily dependent on grain-size. In the brittle-fracture regime, the stress-strain relationship is linear, with fracture occurring at the ultimate strength. Larger grains and strain rates greater than 10 ${ }^{3} \mathrm{~s}^{-1}$ lower the ultimate, or fracture, stress in the brittle regime. By changing the strain rate from $10^{-3}$ to $10^{-1} \mathrm{~s}^{-1}$ at $-10^{\circ} \mathrm{C}$, the compressive fracture strength decreases by approximately $30 \%$. Schulson also reported an increase 


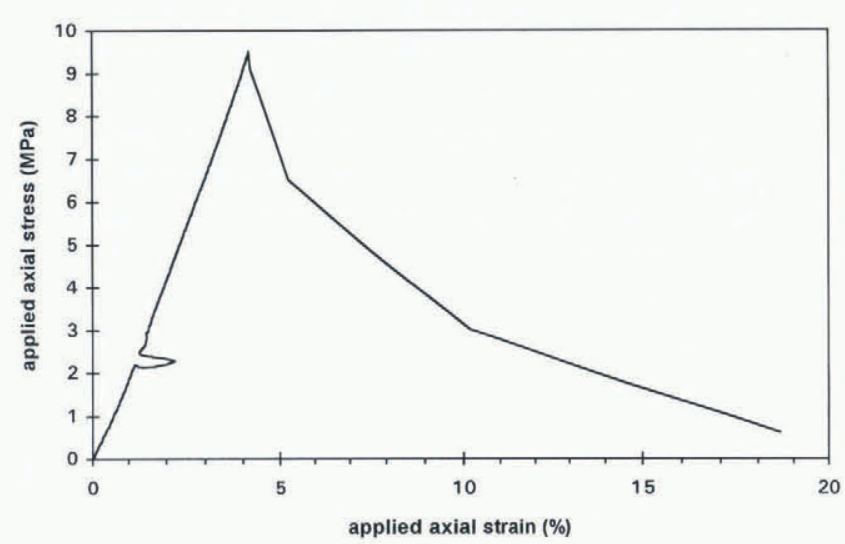

Fig. 9. Stress-strain curve from ice at a depth of 10.5 $15.5 \mathrm{~cm}$; extracted at the south end of the runway $(3050 \mathrm{~m})$. Applied loading rate was $44.5 \mathrm{kN}^{-1}$.

in fracture stress with decreasing temperature. The range of grain-sizes that were tested was $1-10 \mathrm{~mm}$ (significantly smaller than the crystals in the runway meltwater ice). For an average grain diameter of $1 \mathrm{~mm}$, the fracture stress is approximately $10 \mathrm{MPa}$. Increasing the grain-size to $7.3 \mathrm{~mm}$ decreases the fracture stress to approximately $6 \mathrm{MPa}$. All samples that were tested in the brittle regime failed at axial strains on the order of $10^{-3}$. All samples also exhibited internal cracking prior to failure and the number of cracks increased with increasing load. Since failure stress is directly proportional to the inverse square root of the grain diameter, one is led to conclude that this dependence indicates a stress-concentration process.

Fracture toughness tests were reported by Hamza and Muggeridge (1979). Ice was grown in the laboratory in $2.69 \mathrm{~m}^{3}$ boxes at approximately $-20^{\circ} \mathrm{C}$. The grain-sizes were 8 and $12 \mathrm{~mm}$. Their results indicate a marked decrease in fracture toughness with increasing deformation rates. At $-20^{\circ} \mathrm{C}$, increasing the crosshead speed from 0.1 to $50 \mathrm{~mm} \mathrm{~min}^{-1}$ changes the average fracture toughness from 416 to $73 \mathrm{kN} \mathrm{m}^{\frac{3}{2}}$ in the $12 \mathrm{~mm}$ diameter ice. These results demonstrate that, if the ice is already internally damaged to some extent, it will continue to fracture more easily under a high applied loading rate.

The addition of confining pressure should tend to

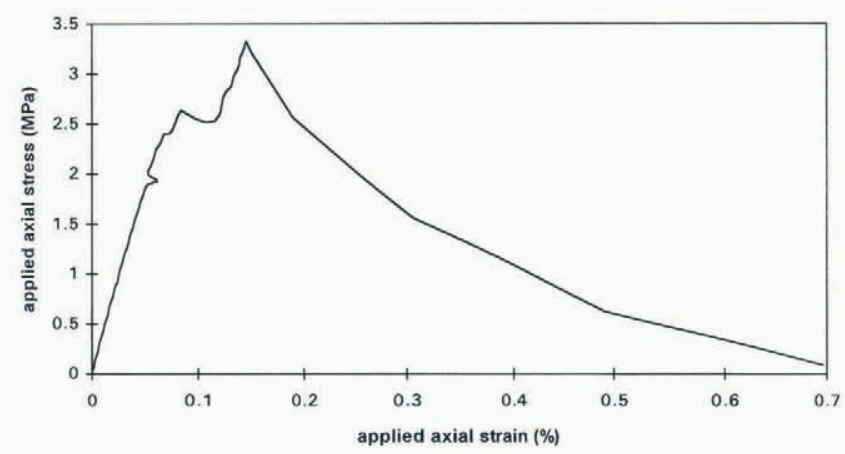

Fig. 10. Stress-strain curve from ice at a depth of 20$27 \mathrm{~cm}$; extracted at the south end of the runway $(3050 \mathrm{~m})$. Applied loading rate was $44.5 \mathrm{kN} \mathrm{s}^{-1}$. shift the ductile-to-brittle transition towards higher strain rates (Kalifa and others, 1992) but, at the strain rate of interest, no data are available. Schulson and others (1991) showed that at high confining ratios (the ratio of confining stress to the maximum normal stress is greater than 0.15 ) the fracture stress does rise but the dependence is not strong. At lower ratios there may be a marked increase in the fracture stress, up to three times the unconfined strength. All of Schulson's tests were performed in the brittle-failure regime at a strain rate of approximately $10^{-3} \mathrm{~s}^{-1}$ and at a temperature of $-40^{\circ} \mathrm{C}$.

When load is applied to a polycrystalline material, the grains that are the most favorably oriented are the first to deform. Slip is able to occur in grains with these orientations because the resolved component of applied stress exceeds the critical resolved shear stress. The movement of dislocations describes this plastic deformation of the grain within the polycrystalline matrix (Jagannadham and Marcinkowski, 1984). The grain boundaries act as obstacles to the progression of dislocation motion because the slip plane is discontinuous at the boundaries. The changes in the grain structure itself are a result of the movement of the lattice dislocations and can be very important in the nucleation of cracks. In this context, there are two types of crack:

1. Transcrystalline: transcrystalline cracks form inside a grain and are not completely contained by a grain boundary.

2. Intercrystalline: intercrystalline cracks form along grain boundaries and coalesce with the boundary.

Low-temperature fracture is believed to be transcrystalline and at higher temperatures intercrystalline behavior is thought to govern. The temperature at which the fracture behavior changes from transcrystalline to intercrystalline is termed the equicohesive temperature (Jagannadham and Marcinkowski, 1984). The equicohesive temperature for ice is not known nor has it been investigated.

Furthermore, the runway ice which was derived from meltwater had large, $c$ axis vertical crystals. In pure compression, basal glide would not occur as the resolved shear stress on the basal plane would be zero. Plastic deformation is then not evident when basal glide is precluded. The movement of dislocations on the prism and pyramidal planes requires more energy to initiate. The result is that the large-grained, $c$ axis vertical ice displays brittle failure.

Recent research on other crystalline solids has clarified the effect of impurities on intercrystalline bonds $\mathrm{Wu}$ and others, 1994). Embrittlement of crystalline materials typically occurs at low temperatures and the addition of impurities plays a distinctive role in embrittlement, even if only trace amounts of the impurity are present. Using a quantum mechanical model, it is possible to calculate the bond energy when an impurity is present and compare that energy to the bond energy in a "pure" crystalline solid. As would be expected, the energy required to break the bond with the impurity is less than the energy required to break a bond in the "pure" crystalline lattice. This effect would be augmented in ice due to the high 
energy associated with hydrogen bonding in ice.

Relatively large quantities of impurities are present in the Pegasus ice at specific depths due to storm winds that deliver mineral dust and sand particles from Black Island. Because ice initially expands and then contracts upon freezing and cooling below $-5^{\circ} \mathrm{C}$, large particles frozen into the ice could debond from the ice structure and create a local stress concentration.

Examination of the failed surface ice on the runway revealed that the ice in these areas probably contained many fractures before it was subjected to proof-rolling. The ice exhibited failure planes that suggested doming and radial (star-like) pattern surface fractures. These features may be the result of natural processes (discussed later), construction activities or some combination. Certainly, some pre-fracturing of the ice occurred during construction of the runway. Aggressive grading was used to level the ice surface to bring it into tolerance for aircraft operations (Blaisdell and Lang, 1994). The grading introduced cracks in the near-surface ice, particularly in areas where former blisters (domed ice with radial surface cracks) were located. At these sites, the grader blade removed as much ice as possible with each pass. Upon encountering radial cracks associated with refrozen melt pools, the grader blade caught these radial cracks and caused them to propagate. On its own, the grading process probably introduced new near-surface cracks as well.

We conclude that the following factors contributed to the brittle failures found in the Pegasus runway ice:

1. Large-grained ice in areas where the natural glacial ice had experienced melting and refreezing.

2. A high rate of loading by moving vehicles, which predicates operating within the brittle-failure regime.

3. Pre-existing internal damage to the ice (from blister development during refreezing and from runway construction activities).

4. The presence of many impurities in the ice structure.

\section{MODELS FOR DEVELOPMENT OF WEAK SURFACE ICE}

Clearly there has been some mechanism or combination of mechanisms at work on the runway ice that has transformed the otherwise sound glacial shelf ice into weak ice. Based on our observation of the ice characteristics, including its behavior under load, we are confident that the weak ice on the runway was formed by freezing of water. At the C-130 and C-141 load level, failure does not occur in ice that is completely glacial in origin (i.e. formed by consolidation of snow).

Specific models for the formation of weak meltwater ice that could cause failure zones on the runway are:

1. Naturally induced surface melt. Surface melting is essentially the formation of a pool or pond of water from ice that melted from the top surface down. During the austral summer, local (selective) melting could, under certain conditions, be caused by a concavity, absorption of radiation by a foreign substance on or slightly below the surface (e.g. mineral particles from Black Island) or an absence of snow cover. Areal extent and depth of melting would be governed by ambient temperatures, cloud conditions (solar input), concentrations of foreign matter or bubbles and deposited snow. If conditions are right for melting of glacial ice, it is possible that free water could also be generated from natural melting of snow in the area.

When conditions allow the water to refreeze, the freezing front probably proceeds inward from the top, sides and bottom, much as an ice cube forms in a freezer. This type of freezing imposes a preferred orientation of the ice crystals. By freezing inward from all directions, the remaining water is under triaxial confinement. Pressure must increase and fracturing of the newly formed ice could be expected. Only in the vertical direction can any displacement occur and, eventually, the ice over the top of the water would be heaved and cracked. The surface of the ice would exhibit doming and cracking.

During the freeze-up process, a distinct gap can form at the interface between the snow-derived shelf ice (the host or container) and the newly refrozen melt. This occurs when the refrozen ice cools to below $-5^{\circ} \mathrm{C}$ and begins to contract. Over time, the surfaces of this gap can become coated by faceted snow crystals produced by sublimation and deposition. This mass flux would occur when a temperature gradient exists in the ice (i.e. the vapor flux results from a vapor gradient, which, in turn, is driven by the temperature gradient). When such crystals are formed in a snowpack, the process is commonly referred to as temperature-gradient (TG) metamorphism and the crystals are called depth hoar and identified as class $7 \mathrm{ch}$ in the international classification system (Colbeck and others, 1990).

Additional weakness in the local ice is probably introduced during this process, particularly at the boundaries as the ice stresses the sides of its "container". During freeze-up, stresses during the expansion phase $\left(0^{\circ}\right.$ to $\left.-5^{\circ} \mathrm{C}\right)$, exerted on the surrounding ice (also at temperatures near $0^{\circ} \mathrm{C}$ ), could cause local deformations in the more ductile, snow-derived ice. This could give rise to internal weakness and fracturing in both the host ice and the refrozen ice.

One would expect the refrozen ice to be very clear, with a high density of thin elongated bubbles and bubble tracks. The ice would be very largegrained and crystals would be vertically oriented, as in lake ice. The ice would also exhibit many internal surfaces displaying a broad spectrum of colors, indicating intercrystalline fracturing due to the heaving stresses exerted by freezing of the confined water. The basal and lateral boundaries of these ice areas would probably be sloped and contain small-scale topographic features indicative of the bottom and sides of a pond.

A simple experiment was run in the Crary Science and Engineering Center (CSEC) facility at McMurdo Station to simulate the formation of this ice and the meltwater ice-glacial ice boundary. 
Water was frozen in a beaker at $-20^{\circ} \mathrm{C}$. The surface of the ice domed and cracked in a star-like formation, as observed at melt-refreeze areas on and near the runway prior to construction. Internal fractures caused by freezing stresses were obvious. Bubbles seemed to form in a pattern following the convection path. $24 \mathrm{~h}$ later a layer of slush-bathcooled water (no solids) was poured on to the top of the domed ice and frozen at $-9^{\circ} \mathrm{C}$. This ice also domed and cracked on the surface and fractured internally. Bubbles formed vertically, with long thin paths, which corresponds to the bubble patterns observed in the field. The double-layered ice was then cooled to $-40^{\circ} \mathrm{C}$. Internal fracturing continued and the ice-ice interface gap developed.

2. Sub-surface melting. Sub-surface melting has been well documented (Paige, 1968; Mellor and Swithinbank, 1989; Bøggild and others, 1994) and described (Brandt and Warren, 1993). It occurs under very specific circumstances and involves a critical balance of surface characteristics, solar radiation (incident, reflected and radiated) and ambient temperature, and is sometimes referred to as the "solid-state greenhouse" effect. Basically, incoming solar radiation penetrates to considerable depth in the ice, while cooling by longwave radiation only occurs at the surface. This creates a situation where temperature can increase with depth for a short distance in the top of an ice sheet. Given the right solar intensity and surface boundary conditions, melting below the surface can be initiated and the water can remain trapped below an intact surface ice layer. Foreign substances (i.e. dirt or rocks) or the trapping of longwave radiation in an air bubble would assist in concentrating radiation absorption at depth.

This model of meltwater formation, then, differs from the first model in that a free water surface is never present. In addition, the only water source is what is melted from within the cavity containing the water. Freeze-up of this water would occur identically to case 1 after the surface water in that situation had frozen to form an ice cover. In this case, the new ice would form underneath a layer of shelf firn and/or glacial ice. It is possible that a sub-surface melt pool could form at a site having formerly (i.e. during a previous austral summer season) experienced melting and refreezing as described in case 1 . Then the top layer of ice would also be meltwater ice (see case 4 below). All of the characteristics of case 1 in regard to the ice formed and the effect on the host ice would be featured under this scenario.

Since up to $0.3 \mathrm{~m}$ of surface ice was removed by the grader during the construction phase of the runway, it is not possible to know from thin-section analyses of cores whether sub-surface melt pools have occurred in the cored areas. However, the gap at $3 \mathrm{~cm}$ depth in the $1830 \mathrm{~m}$ core could represent the top of a sub-surface melt pool that formed in previously melted and refrozen ice. The optimum depth of formation of sub-surface melt pools at this site is unknown.
3. Artificial pond formation with slush surface. Intentional creation of a pond through human action would certainly lead to the circumstances described in case 1. In addition, the free water would likely be warmer than in case 1 and therefore cause melting of the ice and snow it contacted. Furthermore, the water, having a lower extinction coefficient and lower albedo than the surrounding snow and ice, would absorb radiation and cause considerable natural heating. Thus, it might be expected that this body of water would cool more slowly than naturally generated meltwater, leading to larger crystals with a stronger orientation. As increased grain-size has been correlated to decreased strength (Schulson, 1990) and $c$ axis vertical grains subjected to loading perpendicular to the basal plane cannot experience basal glide, this would create the weakest type of meltwater ice.

Runway cores in areas where failures were most concentrated show that the new, weak ice was a mixture of snow and water at the surface, as evidenced by occasional larger ( $1-1.5 \mathrm{~cm}$ diameter) spherical bubbles in addition to the elongated bubbles. Some of the largest bubbles also display frost on their surfaces. The ice is still mostly clear (i.e. it is not as cloudy as the shelf firn and glacial ice). The thin-section analysis of the $1830 \mathrm{~m}$ ice core demonstrates this pattern with a distinct boundary at the meltwater ice-glacial ice interface occurring at a depth of $40 \mathrm{~cm}$. This area was deliberately flooded during runway construction. The slush surface is also quite apparent in the upper horizon of the $1830 \mathrm{~m}$ core.

Two more simple experiments were performed in the CSEC in an attempt to reproduce this type of surface ice. First, shaved ice from the ice-maker was used to make a slush bath in a Pyrex beaker and was allowed to freeze for $24 \mathrm{~h}$ at $-9^{\circ} \mathrm{C}$. The expansion of the ice broke the beaker. The ice was milky due to the number of bubbles and internal fracturing, and large bubbles (up to $0.75 \mathrm{~cm}$ in diameter) were included. The surface was very lumpy and did not exhibit a central dome. Three discrete internal failure planes were visible and were continuous through the entire sample. This ice could easily be mistaken on a macroscopic scale for the type of naturally occurring, near-surface ice in the McMurdo Ice Shelf. It was, therefore, of interest to use real snow instead of shaved ice for the experiment in order to observe the macroscopic differences. On 10 February 1993 a snowstorm enveloped McMurdo Station and freshly fallen snow was taken into the laboratory, placed in a beaker and irrigated with supercooled water. The sample was left at $-9^{\circ} \mathrm{C}$ to freeze for $24 \mathrm{~h}$. The resulting ice was very similar to that in the shaved ice and water mixture, although the entrained bubbles were much larger (up to $2 \mathrm{~cm}$ in diameter). Internal fracturing was also apparent at about the same frequency as in the other slush mixture.

4. Subsequent episodes of melt at a given location. This is cognate to the scenario described in cases 1 and 2 
but the host stratum is also composed of frozen meltwater. The lower melt-pool boundary could be distinguished by the same type of gap with depthhoar type crystals. It may be surmised that the host ice resulted from a previous (prior austral summer season) melting episode.

In examining the thin section of the top $5 \mathrm{~cm}$ of runway ice at $1830 \mathrm{~m}$, it is apparent that the large, vertically oriented crystals are discontinuous at $3 \mathrm{~cm}$ depth. In naturally occurring lake ice, single crystals can be found as long as $40 \mathrm{~cm}$, extending throughout the entire thickness of the ice (Gow and Langston, 1977). Thus, multiple melt-refreeze episodes must have occurred at the site of this core either as the result of natural forces or from phased delivery of manufactured meltwater when flooding during construction. Under natural conditions, this may happen if the surface dome of the ice remains exposed for several years (i.e. no natural snow cover), so that remelting may occur to some depth through either mechanism 1 or 2. This has been observed in ice cores from the refrozen melt pools west of the runway.

\section{EVIDENCE SUPPORTING MELTWATER OCCURRENGE}

At the Pegasus runway, summer conditions are key to the development of meltwater. We have observed the ice shelf in the area of the Pegasus runway during austral summers since 1989. Historical accounts of the area are also available (Mellor and Swithinbank, 1989). The runway is situated in a transition zone between regions of accumulation and ablation (Blaisdell and others, $1995)$. It was carefully sited in this zone to assure that a thin, but permanent and complete, snow cover was present. Only a few hundred meters from the runway toward the ablation zone (west), the snow cover becomes patchy, with areas of exposed ice. During December and the first half of January, relatively high temperatures (near melting) and intense sunshine predominate at McMurdo Station. Under these conditions, exposed ice (no snow cover) absorbs radiation and can reach the melting point. In the immediate vicinity of the Pegasus runway, when melting occurs it usually takes place at a level slightly below the top of the ice (Paige, 1968). Melting can often become widespread and can create very large melt pools. Our experience at this site indicates that naturally triggered surface melt is rare, only occurring during very "hot" summers, or where concentrations of pollutants (mineral dust, oil, fuel or coolants) are located. Free surface water in the transition zone generally does not flow far, often only to ponding areas or areas with snow cover where it refreezes (Blaisdell and others, 1995). Sub-surface melt water, however, persists until the solar intensity and ambient temperatures begin to fall. Only then can the water lose enough energy to refreeze.

The sub-surface refreezing process is slow, since the mass of water is completely isolated within the glacier. Melting seems to initiate, when it occurs naturally, in mid- to late December, and freeze-up may not be complete until the end of February. Commonly, heaving

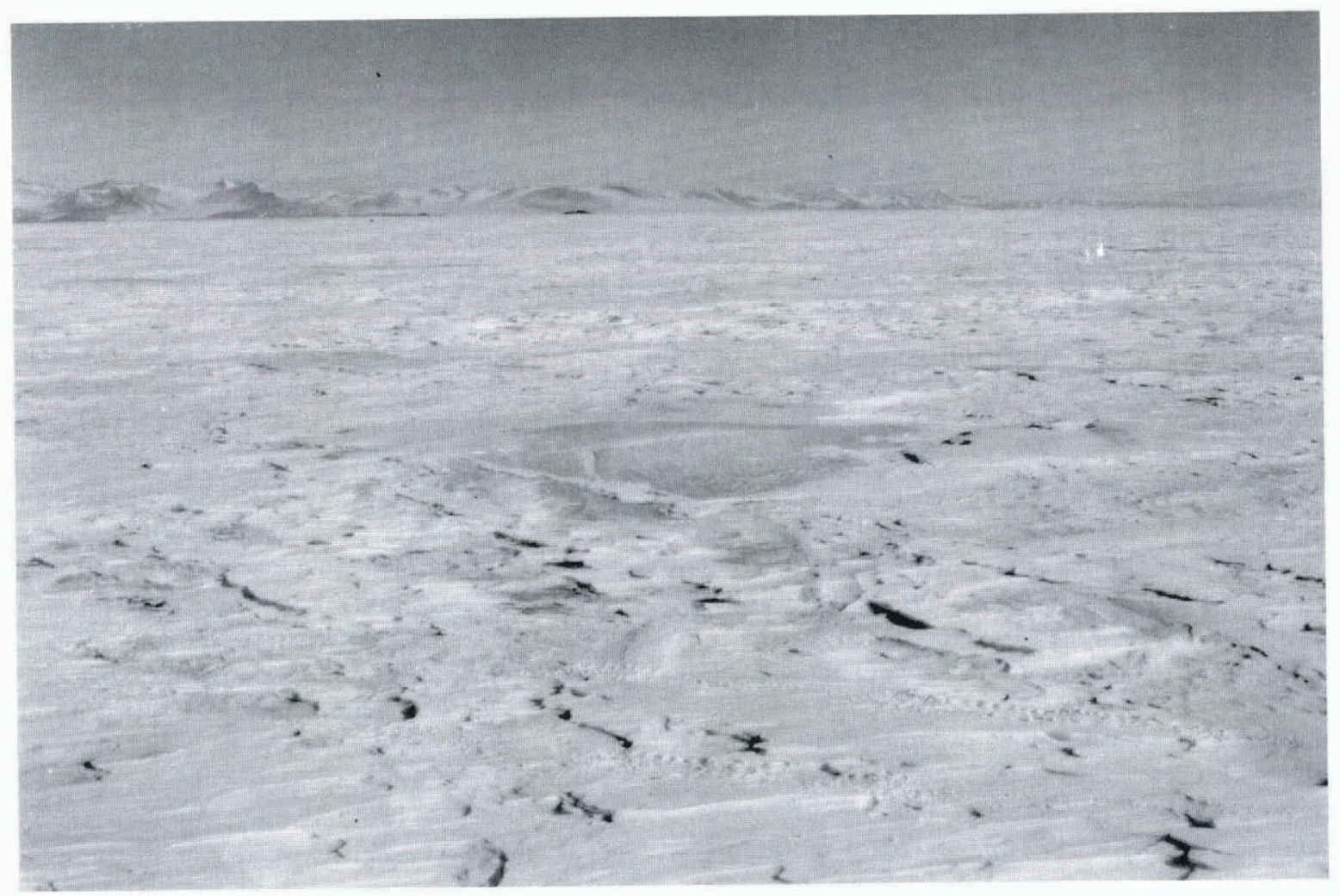

Fig. 11. Site of former melt pools on the ice shelf. They are easily identified by surface blisters that can frequently be very large and have distinct radial tension cracks. 

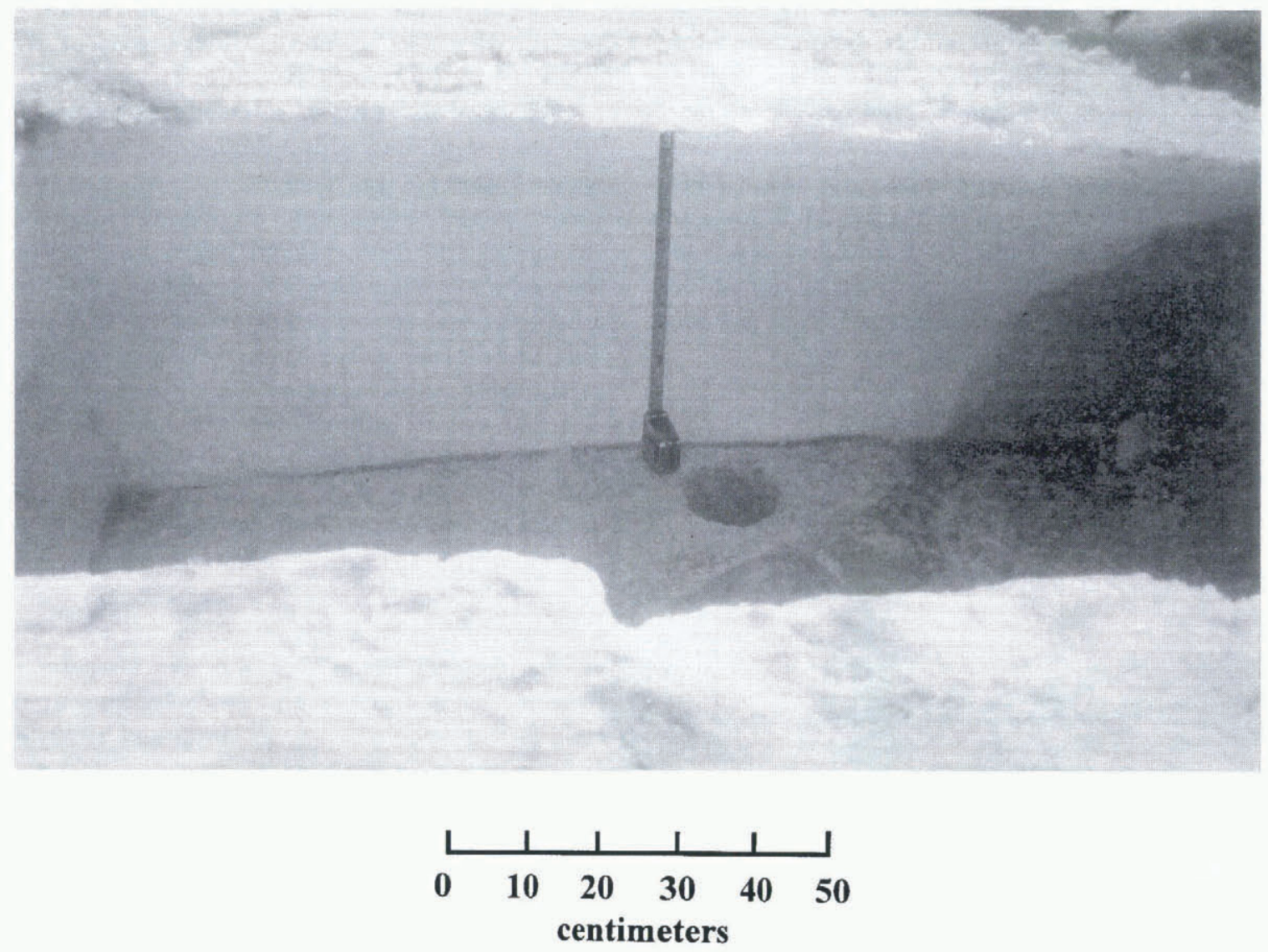

Fig. 12. Cross-section of ice blister showing gap between upper meltwater ice and lower glacial ice.

occurs during refreezing. Sites of former melt pools on the ice shelf can easily be identified by surface blisters that can frequently be very large and have distinct radial tension cracks (Fig. 11).

Because of the spotty occurrence of melt pools in the particular area of the Pegasus runway, some sites (those with a chronic lack of snow cover) may form melt pools annually. Other areas may have never experienced melting and refreezing. A giant cross-section of the area in the winter, when everything is frozen, would most likely display elongated pods of large-crystal "blue" ice scattered along near the surface and embedded within fine-grained, milky glacial ice. Klokov and Diemand (1994) have dissected a frozen melt pool and described its features, including a gap at the meltwater-glacial ice boundary (Fig. 12).

Surface meltwater on the runway occurred at least once in the recent past. Construction activities during the 1990-91 austral summer triggered vast surface melting of snow and ice. In addition, water was produced in a snow melter and poured out on to the natural ice surface to "fill" a large depression and thereby avoid a tremendous amount of ice grading to achieve a smooth runway. A combination of large areas of exposed ice (during rough grading), the introduction of huge quantities of warm water, a great deal of activity by heavy equipment and a "warm, sunny summer" led to rivers and lakes of free surface water on and near the runway.

The majority of surface-ice failures occurred in the 1220 to $1830 \mathrm{~m}$ region of the runway. This is the area that was flooded with manufactured snowmelt to fill and level the basin. The snowmelt was relatively warm, so snow was subsequently blown on to the pond surface in an attempt to cool the water and to generate a slush bath.

\section{CONCLUSIONS}

The majority of surface failures that occurred during the proof-rolling of the Pegasus runway during November 1992 can be attributed to the existence of "lake ice" in the 1220 to $1830 \mathrm{~m}$ region of the runway. This ice formed as the result of deliberate ponding during construction activities in the 1991-92 austral summer. A natural depression was filled with manufactured snowmelt to level the surface to grade. Thin-section analyses show that this ice is composed of large crystals with vertically oriented $c$ axes. Large-grained ice is comparatively weak in compression, according to a number of authors. Natural melt-pool formation during austral summer seasons prior to runway construction appears to be the second most likely source for weak meltwater ice on the runway. Although the frequency of core sampling and thin-section analysis was not sufficient to distinguish these regions from the frozen pond water, at 3050 and $0 \mathrm{~m}$ many isolated failure regions were macroscopically identified as meltwater-ice zones. The formation of melt pools is a common occurrence in areas adjacent to the runway, especially to the west.

It is unlikely in the future that there will be a need to generate artificial ponds of water on the runway. Since melt pools and ponds would obviously destroy the 
Pegasus runway, the primary objective of the runway management crew should be to protect the runway from melt-pool formation (sub-surface and surface types) during periods of peak insolation. This can be accomplished by covering the runway with snow during late November, December and early January. Runway design criteria call for it to be covered with a $35-40 \mathrm{~cm}$ layer of snow from the end of November until mid-January. The snow reflects a larger percentage of the incoming radiation and attenuates what is absorbed, thus protecting against melting of the ice (Fig. 13).

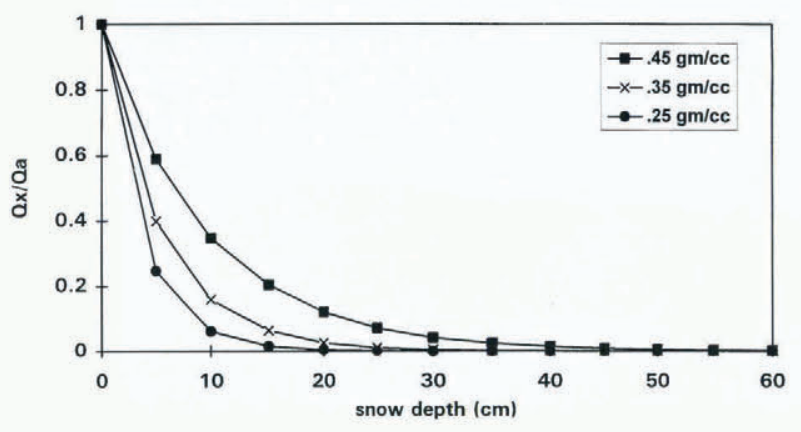

Fig. 13. Ratio of radiation intensity absorbed at depth $x,\left(Q_{x}\right)$ to intensity absorbed at snow surface $\left(Q_{a}\right)$ as a function of snowpack thickness and density.

Brittle failure occurs in ice when a high rate of loading is applied to large-grained ice and the ultimate strength is reached. If some internal damage already exists, and impurities are present in the ice structure, the fracture strength is further reduced. With limited samples to test, we were unable to determine the exact strength of the meltwater ice on the runway. Tests on the glacial ice at the $3050 \mathrm{~m}$ area of the runway (south end) showed fracture strengths ranging from 3.4 to $10 \mathrm{MPa}$ under a $44.5 \mathrm{kN} \mathrm{s}^{-1}$ loading rate. The failure mode in this ice was brittle, indicated by fracture in the linear part of the stress-strain relationship. However, the strength obtained in these tests should be adequate to support the $1.4 \mathrm{MPa}$ tire pressure requirement for the $\mathrm{C}-141$.

It is likely that the proof-cart failures resulted from the presence of the gap formed at the meltwater ice-glacial ice contact. By loading the meltwater ice as a beam or plate, it is under tension below the neutral axis and has significantly less strength. To make matters worse, the close spacing of the proof-cart wheels probably results in placement of the load of two to four tires on the ice over a gap. Thus, as shown from our compressive strength results, the meltwater ice is strong enough to support the contact pressure of the proof cart but the ice does not have sufficient strength in bending to resist the load carried by one or more proof-cart wheels.

It would be expected that the majority of the ice would crumble when the load on an ice plate exceeds the ice's flexural strength. Furthermore, the ice would break up throughout the thickness of the plate, not just at the surface where the contact load was high. Once the proof cart moved out of the area underlain by a gap, the meltwater ice, even with its internal flaws, impurities and large, aligned crystals would again be loaded in com- pression only and could adequately support the load. This scenario fits well with our observations of ice failures produced by the proof cart.

It is possible to repair satisfactorily failed areas using an "ice composite" with a high solids fraction and cold water. Failed ice was removed from the area, broken into smaller pieces and the area was repacked tightly with the ice chunks and snow. Cooled water was slowly added to the solids, allowing air to escape. This process resulted in a high-strength ice-composite pavement that was successfully proof-rolled in all cases. The goal of this patching procedure was to generate a "binder" of randomly oriented, small-grained ice that would entrain the medium-sized, large-crystal ice chunks. In effect, the patch was similar to a concrete/aggregate mixture.

Successful on-site evaluation of the weak surface ice and the rapid, effective repair of the runway surface culminated with wheeled-aircraft operations on the Pegasus runway in February 1993 and for the duration of the 1992-93 summer season. No further ice failures have occurred as the result of proof-rolling at the C-141 level during the 1993-94, 1994-95 and 1995-96 seasons or from frequent wheeled flights by C-130 and C-141 aircraft. The ability to use wheeled aircraft has provided significant savings and enhanced capabilities to the U.S. Antarctic Program.

\section{ACKNOWLEDGEMENTS}

This work was sponsored by the U.S. National Science Foundation, Office of Polar Programs, Operations Section, and by the U.S. Army Cold Regions Research and Engineering Laboratory.

\section{REFERENCES}

Blaisdell, G. L., R. Lang, G. Crist, K. Kurtti, R. Harbin and D. Flora 1994. Construction of a glacial ice runway and wheeled flight operations at McMurdo, Antarctica. In Proceedings of the Sixth Symposium on Antarctic Logistics and Operations, Rome, Italy, 29-31 August 1994. Washington, DC, Council of Managers of National Antarctic Programs (COMNAP), 231-242.

Blaisdell, G. L., V. Klokov and D. Diemand. 1995. Compacted snow runway technology on the Ross Ice Shelf near McMurdo, Antarctica. In Elliot, D. H. and G. L. Blaisdell, eds. Contributions to Antarctic research IV. Washington, DC, American Geophysical Union, 153-173. (Antarctic Research Series 67.)

Bøggild, C. E., J. G. Winther, K. Sand and H. Elvehøy. 1994. Blue-ice field, Dronning Maud Land, Antarctica. ICE, 106, 7.

Brandt, R. E. and S. G. Warren. 1993. Solar-heating and temperature profiles in Antarctic snow and ice. 7. Glaciol., 39 (131), 99-110.

Colbeck, S. C. and 7 others. 1990. The international classification for seasonal snow on the ground. Wallingford, Oxfordshire, International Association of Scientific Hydrology. International Commission on Snow and Ice.

Gow, A.J. and D. Langston. 1977. Growth history of lake ice in relation to its stratigraphic crystalline and mechanical structure. CRREL Rep. $77-1$

Hamza, H. and D. B. Muggeridge. 1979. Plane strain fracture toughness $\left(\mathrm{K}_{\mathrm{ic}}\right)$ of fresh water ice. In POAC 79. The Fifth International Conference on Port and Ocean Engineering under Arctic Conditions, August 13-18, 1979. Proceedings. Vol. 1. Trondheim, University of Trondheim and Norwegian Institute of Technology, 697-707.

Jagannadham, K. and M. K. Marcinkowski. 1984. Unified theory of fracture. Material Science Surveys, 1, 795.

Kalifa, P., G. Ouillon and P. Duval. 1992. Microcracking and the failure of polycrystalline ice under triaxial compression. J. Glaciol., 38 (128), 
$65-76$.

Klokov, V. and D. Diemand. 1995. Glaciology of the McMurdo Ice Shelf in the area of air operations. In Elliot, D.H. and G.L. Blaisdell, eds. Contributions to Antarctic research IV. Washington, DC, American Geophysical Union, 175-195. (Antarctic Research Series 67.)

Mellor, M. and C. Swithinbank. 1989. Airfields on Antarctic glacier ice. CRREL Rep. 89-21.

Nuttall, J. B. and N. R. Morgenstern. 1972. Compression tests on fresh water ice. Calgary, Alta, Arctic Petroleum Operators' Association. (Report 16-2.)
Paige, R.A. 1968. Sub-surface melt pools in the McMurdo Ice Shelf, Antarctica. F. Glaciol., 7(51), 511-516.

Schulson, E. M. 1990. The brittle compressive fracture of ice. Acta Metall. Materialia, 38(10), 1963-1976.

Schulson, E. M., D.E. Jones and G.A. Kuehn. 1991. The effect of confinement on the brittle compressive fracture of ice. Ann. Glaciol., 15, 216-221.

Wu, R., J. Freeman and G. B. Olson. 1994. First principles determination of the effects of phosphorus and boron on iron grain boundary cohesion. Science, 265, 376-380.

MS received 31 July 1995 and accepted in revised form 20 January 1996 